\title{
IL-1B rs2853550 polymorphism contributes to esophageal cancer susceptibility in Chinese Han population of Northwest China
}

Ruimin Zhao ${ }^{1 \dagger}$, Xin Chen ${ }^{2 \dagger}$, Wanli Ren ${ }^{1}$, Hao Dai ${ }^{1}$, Huajing $\mathrm{Li}^{1}$, Honghui $\mathrm{Li}^{1}, \mathrm{Ai}_{\mathrm{Ji}}{ }^{3}$, Yue $\mathrm{Wu}^{4}$, Peng Han ${ }^{1 *}$ and Yuan Shao ${ }^{1 *}$ (i)

\begin{abstract}
Background: Esophageal cancer (EC) is one of the most common human cancers, with a particularly aggressive behavior and increased incidence worldwide. The aim of this study was to assess the associations of singlenucleotide polymorphisms (SNPS) in IL-1B with the risk of EC in a northwest Chinese Han population.

Methods: In order to evaluate the correlations between IL-1B polymorphisms and EC risk, an Agena MassARRAY platform was used to determine the genotype of the candidate SNPs among 384 EC patients and 499 controls. The associations between $I L-1 B$ variants and EC risk were examined using logistic regression analysis with adjustment for gender and age. Haplotype construction and analysis were performed to detect the potential associations between haplotypes within IL-1B and EC susceptibility. Additionally, bioinformatics databases were used for gene expression analysis and SNP functional prediction.

Results: A significant relationship was found between IL-1B rs2853550 and an increased risk of EC in the allele model [odds ratio $(\mathrm{OR})=1.38,95 \%$ confidence interval $(95 \% \mathrm{Cl}): 1.01-1.89, p=0.041)$, the codominant model $(\mathrm{A} / \mathrm{G}$, $\mathrm{OR}=1.63,95 \% \mathrm{Cl}: 1.10-2.42, p=0.011)$, and the dominant model $(\mathrm{OR}=1.49,95 \% \mathrm{Cl}: 1.02-2.18, p=0.041)$. Functional analysis revealed the potential effects of rs2853550, which further reinforced its influence on EC susceptibility. However, there were no statistically significant differences for other SNPs or haplotypes between EC cases and healthy controls. Expression analysis conducted with dataset indicated that the expression level of IL-1B was higher in EC cases than that in normal samples.
\end{abstract}

Conclusions: This study demonstrated that rs2853550 in IL-1B might increase EC susceptibility in the Chinese Han population of Northwest China.

Keywords: IL-1B, Polymorphisms, Esophageal cancer, Chinese Han population, Case-control study

\footnotetext{
*Correspondence: penghanent@hotmail.com; shaxiaoying1976@163.com

${ }^{\dagger}$ Ruimin Zhao and Xin Chen joint first authors

'Department of Otolaryngology \& Head Neck, the First Hospital of Xi'an Jiaotong University, \#227 West Yanta Road, Xi'an 710061, Shaanxi Province,

China

Full list of author information is available at the end of the article
}

(C) The Author(s). 2020 Open Access This article is licensed under a Creative Commons Attribution 4.0 International License, which permits use, sharing, adaptation, distribution and reproduction in any medium or format, as long as you give appropriate credit to the original author(s) and the source, provide a link to the Creative Commons licence, and indicate if changes were made. The images or other third party material in this article are included in the article's Creative Commons licence, unless indicated otherwise in a credit line to the material. If material is not included in the article's Creative Commons licence and your intended use is not permitted by statutory regulation or exceeds the permitted use, you will need to obtain permission directly from the copyright holder. To view a copy of this licence, visit http://creativecommons.org/licenses/by/4.0/. 


\section{Background}

Esophageal cancer (EC) is the eighth most common human cancer, and its incidence rate has significantly increased in recent years (Parkin et al. 2005). It is noteworthy that during this time, most cases of EC have occurred in developing countries, and more than onehalf of all EC cases were diagnosed in China, with EC being more common in males than in females, and more common in urban areas than in rural areas. Moreover, a previous study has reported that the 5-year survival rate of EC patients is extremely poor $(<20 \%)$ (Jemal et al. 2008). There are various habits that may contribute to esophageal tumorigenesis, two of these are alcohol consumption and cigarette smoking (Mayne et al. 2001). However, conclusive epidemiological studies have revealed that only a small proportion of individuals with such habits develop EC, which suggests that genetic aberrations, such as single-nucleotide polymorphisms (SNPs), are responsible factors that play important roles in EC development (An et al. 2015; Geng et al. 2015; Wang et al. 2016a; Wang et al. 2016b).

The IL-1 (interleukin-1) family exerts a pivotal effect on inflammatory and immune responses by affecting antigen recognition patterns and lymphocyte functions (Zheng et al. 2013). The $I L-1 B$ gene, which is located on human chromosome $2 \mathrm{q} 13$, belongs to a prototypical, multifunctional IL-1 gene cluster. The IL-1 beta (IL-1 $\beta$ ) protein, encoded by $I L-1 B$, functions as a secreted protein during both acute and chronic inflammation in the human body (Nicklin et al. 2002). IL$1 \beta$ can be produced by different types of cells, such as T-lymphocytes, B-lymphocytes, natural killer cells, and neutrophils, but is primarily produced by blood monocytes and tissue macrophages (Bird et al. 2002). Previous studies have uncovered several significant $I L$ $1 B$ polymorphisms associated with diverse diseases in different cohorts worldwide. Majeed et al. have found a common polymorphic allele in the regulatory region of $I L-1 B$ that is associated with increased production of IL-1 $\beta$ in cervical lesions among European females (Majeed et al. 1999). IL-1B rs16944 has been demonstrated to affect $I L-1 B$ expression and was found to be associated with increased EC risk in an Irish population (Azim et al. 2004). Landvik et al. have found that individuals with the rs 1143623 "C" allele of $I L-1 B$ have a reduced risk of lung cancer, with an odds ratio (OR) of 0.69 (95\% CI: 0.51-0.92) (Landvik et al. 2008). Furthermore, Ito et al. have demonstrated that the $I L-1 B$ rs1143627 "A" allele plays a protective role in the development of breast cancer among postmenopausal women (Ito et al. 2002). Additionally, $I L-1 B$ variants have been proved to be associated with gastric cancer susceptibility (He et al. 2011a) and inflammatory bowel disease (Nemetz et al. 1999).
Although the significant evidence has be detected between $I L-1 B$ polymorphisms and multiple diseases in numerous populations. The relationships between $I L-1 B$ polymorphisms and EC susceptibility are seldom reported in the Han population from northwest China. Therefore, we performed the research that aimed to discover the potential roles of $I L-1 B$ variants in EC susceptibility. After reading the previous publications of $I L-1 B$ polymorphisms, we selected several SNPs as the candidate variations (Sasayama et al. 2011; Hovhannisyan et al. 2017; Kim et al. 2012; Langmia et al. 2016; PerezRamirez et al. 2017). Subsequently, these SNPs were searched in databases for detailed information and evaluated for primer design. In this study, we aimed to investigate the relationships between seven SNPs within $I L-1 B$, namely rs2853550, rs1143643, rs3136558, rs1143630, rs1143627, rs16944, and rs1143623, and the risk of EC in a Han population from northwest China. Our results are supposed to provide significant evidence for the innate role of $I L-1 B$ and its polymorphisms in EC pathogenesis.

\section{Materials and methods Study subjects}

This case-control study involved a Chinese Han population consisting of 384 EC patients (308 males and $76 \mathrm{fe}-$ males) and 499 controls (301 males and 198 females). All cases have been histopathologically diagnosed with EC and were consecutively enrolled from the Shaanxi Provincial People's Hospital. It should be noted that patients who had undergone radiotherapy and chemotherapy or who had metastasized cancer were excluded from this study. Four hundred ninety nine control individuals were recruited from the physical examination center of the same hospital during the same period. None of the controls had personal or family cancer history, autoimmune, chronic or metabolic diseases. All the participants were permanent residents living in Shaanxi Province and had unrelated Chinese Han ancestries. Additionally, any patients or controls who recently received a blood transfusion were excluded from this study.

\section{Ethics approval and consent to participate}

All participants were informed in writing and verbally of the procedures and purpose of this study. Signed informed consent documents were obtained from both patients and healthy individuals. Study protocols were approved by the Ethics Committee of the First Hospital of Xi'an Jiaotong University and Shaanxi Provincial People's Hospital. Our research also complied with the ethical standards of the Ethics Committee and World Medical Association Declaration of Helsinki. All the 
subsequent research analyses were carried out in accordance with the approved guidelines and regulations.

\section{DNA isolation and SNP genotyping}

Genomic DNA was isolated from peripheral blood samples using the GoldMag-Mini Purification kit (GoldMag Co. Ltd., Xi'an city, China), according to the manufacturer's instructions. DNA concentrations were measured using a NanoDrop 2000 (Thermo Scientific, Waltham, Massachusetts, USA) at a wavelength of $260 \mathrm{~nm}$. According to the previous publications, several polymorphisms in $I L-1 B$ were selected as the candidates (Sasayama et al. 2011; Hovhannisyan et al. 2017; Kim et al. 2012; Langmia et al. 2016; Perez-Ramirez et al. 2017). We searched these SNPs in 1000 Genomes database (http://www.internationalgenome.org/) (Fairley et al. 2019) and dbSNP database (https://www.ncbi.nlm. nih.gov/snp/) (Sherry et al. 2001) to screen the loci with minor allele frequencies $(\mathrm{MAFs})>0.05$, and designed the primers with Agena Bioscience Assay Design Suite software, version 2.0 (https://agenacx.com/online-tools/) for amplification and single-base extension reactions (Gabriel et al. 2009). PCR primers for the seven SNPs are showed in Supplementary Table S1. The SNPs whose MAF $<0.05$ and primers cannot be designed were excluded. IL-1B polymorphisms rs2853550, rs1143643, rs3136558, rs1143630, rs1143627, rs16944, and rs1143623, of which the MAFs were greater than $5 \%$ in the global population, were eventually eligible and genotyped in EC patients and healthy controls. SNP genotyping was conducted using the MassARRAY Nanodispenser and iPLEX platform (Agena Bioscience, San Diego, CA, USA), following the manufacturer's protocol (Gabriel et al. 2009), and data were analyzed using Agena Bioscience TYPER software, version 4.0 (Gabriel et al. 2009; Thomas et al. 2007).

\section{Statistical analysis}

SPSS 17.0 (SPSS, Chicago, IL, USA) were used for preliminary statistical analyses. Allele frequency of each SNP in the control group was calculated and Fisher's exact test was performed to evaluate the departure from Hardy-Weinberg equilibrium (HWE). Variants with an HWE $p$-value greater than 0.05 were further analyzed. Fisher's exact test and $x^{2}$ test were used to assess the differences in allele and genotype frequencies between patients and controls. The allele with low frequency was regarded as the minor allele " $\mathrm{A}$ ", and the other was the wild allele "B". Furthermore, four genetic models (codominant: $\mathrm{BB}$ vs. $\mathrm{AB}$ vs. $\mathrm{AA}$, dominant: $\mathrm{BB}$ vs. $\mathrm{AB}+\mathrm{AA}$, recessive: $B B+A B$ vs. $A A$, and log-additive: for each $A$ increase) were employed using SNPstats software (https://www.snpstats.net/start.htm) to estimate the relationship between each SNP and EC risk. Logistic regression analysis was carried out for association examinations, and odds ratio (OR) and 95\% confidence intervals $(95 \%$ CIs) were calculated using the logistic regression model (Bland and Altman 2000). As covariates, age and gender were adjusted to accurately assess statistical significance. Two-sided $p$ values less than or equal to 0.05 were considered statistically significant for all statistical tests. Finally, Haploview software, version 4.2, and the SHEsis software platform (http://analysis. bio-x.cn/myAnalysis.php) (Yong and Lin 2005) were used for linkage disequilibrium (LD) assessments, and haplotype constructions and analyses.

\section{Bioinformatics analysis of $I L-1 B$ and functional assessments of SNPs}

The public GEPIA database (Gene Expression Profiling Interactive Analysis; http://gepia.cancer-pku.cn/) (Tang et al. 2017) was used to analyze $I L-1 B$ expression differences between EC tumors and normal tissues. For SNP functional assessment, RegulomeDB (https://www.regulomedb.org/regulome-search/) (Boyle et al. 2012) and HaploReg (https://pubs.broadinstitute.org/mammals/ haploreg/haploreg.php), version 4.1 (Ward and Kellis 2011), were used to predict the possible roles of the SNPs selected in this study.

\section{Results \\ Population characteristics}

The age and gender distributions of the 384 EC patients and 499 control subjects are listed in Table 1. The case and control groups were 80.3 and $60.3 \%$ male, respectively. The mean age $[ \pm$ standard deviation $(\mathrm{SD})]$ of the case group was $60.81 \pm 8.84$ years at the time of diagnosis and that of the control group was $51.47 \pm 11.84$ years at recruitment. Statistical differences in age and gender existed between the two studied groups, however, were adjusted in subsequent analyses.

\section{IL-1B SNPs and EC risk}

Basic characteristics and allele frequencies of $I L-1 B$ polymorphisms are presented in Table 2. SNP rs1143643

Table 1 Distribution of age and gender in EC patients and controls

\begin{tabular}{llllll}
\hline Variable & Cases $(\mathrm{n})$ & $\%$ & Controls $(\mathrm{n})$ & $\%$ & $p$ value \\
\hline Total & 384 & & 499 & & \\
Gender & & & & & $<0.01^{\text {a }}$ \\
Female & 76 & 19.7 & 198 & 39.7 & \\
Male & 308 & 80.3 & 301 & 60.3 & \\
Mean Age (years) & 60.81 & & 51.47 & & $<0.01^{\text {b }}$ \\
Standard Deviation & 8.84 & & 11.84 & & \\
\hline
\end{tabular}

$p^{\mathrm{a}}$-value: $p$-value obtained using $x^{2}$ test

$p^{\mathrm{b}}$-value: $p$-value obtained from independent sample $t$-test 
Table 2 Basic characteristics and allele frequencies of the seven IL-1B SNPS

\begin{tabular}{|c|c|c|c|c|c|c|c|}
\hline \multirow[t]{2}{*}{ SNP } & \multirow[t]{2}{*}{ Gene } & \multirow[t]{2}{*}{ Chromosome } & \multirow[t]{2}{*}{ Allele } & \multicolumn{2}{|c|}{ Minor Allele Frequency } & \multirow[t]{2}{*}{ OR $(95 \% \mathrm{Cl})$} & \multirow[t]{2}{*}{$p^{a}$} \\
\hline & & & & Case & Control & & \\
\hline rs2853550 & IL-1B & $2 q 13$ & $A<G$ & 0.117 & 0.088 & $1.38(1.01-1.89)$ & 0.041 \\
\hline rs1143643 & IL-1B & $2 q 13$ & $C<T$ & 0.471 & 0.470 & $1.00(0.83-1.22)$ & 0.949 \\
\hline rs3136558 & IL-1B & $2 q 13$ & $G<A$ & 0.397 & 0.374 & $1.10(0.90-1.33)$ & 0.334 \\
\hline rs1143630 & IL-1B & $2 q 13$ & $\mathrm{~T}<\mathrm{G}$ & 0.156 & 0.159 & $0.98(0.76-1.27)$ & 0.861 \\
\hline rs1143627 & IL-1B & $2 q 13$ & $G<A$ & 0.453 & 0.479 & $0.91(0.75-1.09)$ & 0.295 \\
\hline rs16944 & IL-1B & $2 q 13$ & $A<G$ & 0.456 & 0.474 & $0.93(0.77-1.12)$ & 0.444 \\
\hline rs1143623 & IL-1B & $2 q 13$ & $G<C$ & 0.362 & 0.399 & $0.85(0.70-1.04)$ & 0.114 \\
\hline
\end{tabular}

SNP Single nucleotide polymorphism, OR Odds ratio, 95\% Cl 95\% confidence interval

$p^{\mathrm{a}}$ values were calculated using $\mathrm{X}^{2}$ test for comparison of the allele distribution frequencies among EC patients and healthy controls Bold italics indicates the SNP with statistical significance $(p<0.05)$

was excluded from this study because of its deviation from HWE $(p<0.05)$ in the control group. We evaluated the correlation between the $I L-1 B$ SNPs and EC susceptibility using four genetic models, hypothesizing that the minor allele of each variant was a risk factor. As showed in Table 2 , the "A" allele of rs 2853550 exhibited an obviously different frequency in patients compared with controls $(11.7 \%$ vs. $8.8 \%)$ and was associated with an increased risk of EC (OR $=1.38,95 \%$ CI: $1.01-1.89, p=0.041)$. Genotype frequencies and risk association results of the selected $I L$ $1 B$ polymorphisms under the four genetic models are provided in Table 3. For variant rs2853550, the frequency of the heterozygous "A/G" genotype in patients was significantly different from that in controls $(22.9 \%$ vs. $14.3 \%$, respectively). Furthermore, compared with the "G/G" genotype in rs2853550, the " $\mathrm{A} / \mathrm{G}$ " genotype contributed to an increased risk of EC after adjusting for age and gender $(\mathrm{OR}=1.63,95 \% \mathrm{CI}: 1.10-2.42, p=0.011)$. Additionally, after correction for age and gender, $I L-1 B$ rs2853550 was showed to be linked to an increased risk of EC based on the results of the dominant model (adjusted $\mathrm{OR}=1.49$, 95\% CI:1.02-2.18, $p=0.041$ ). However, $I L-1 B$ variants rs1143643, rs3136558, rs1143630, rs1143627, rs16944, and rs1143623 did not show evidence of a correlation with EC susceptibility in this cohort.

\section{EC risk and IL-1B haplotypes on chromosome $2 \mathrm{q} 13$}

Finally, four $I L-1 B$ polymorphisms (rs1143630, rs1143627, rs16944, and rs1143623) mapped to a 4-kb LD block, forming four haplotypes with frequencies greater than 0.05 among our subjects (Table 4). In Fig. 1, the red squares in the $I L-1 B$ LD block indicated significant linkages between the four SNPs. Unfortunately, there were no statistically significant correlations between any $I L-1 B$ haplotype and EC risk in our cohort (Table 4).

\section{Potential functional roles of the selected IL-1B SNPs}

Using the RegulomeDB and HaploReg databases, we assessed the possible functions of the seven selected
SNPs, and the results are listed in Supplementary Table S2. All variants were predicted to have biological functions, according to the combined annotations of the two online tools. Their functional importance, particularly those of rs2853550, rs1143627, and rs16944, was evident from the low RegulomeDB score and the prediction of multiple functions in HaploReg.

\section{Expression analysis of IL-1B gene in EC}

GEPIA analysis revealed a significant difference in $I L-1 B$ expression levels between $182 \mathrm{EC}$ tumors and 286 normal tissues (Fig. 2). The expression level of $I L-1 B$ was increased in tumor samples when compared with controls $(p<0.001)$.

\section{Discussion}

In the present study, we genotyped seven polymorphisms in $I L-1 B$ and systematically evaluated their correlations with EC risk in a Chinese Han population of Northwest China. Our data yielded statistical evidence of an association between the SNP rs2853550 and increased risk of EC for the first time. Furthermore, functional analysis showed the potential effect of rs 2853550 polymorphism, which strengthens the prospect that rs2853550 contributes to EC susceptibility. Additionally, we evaluated the $I L-1 B$ expression pattern in EC and normal samples using convincing bioinformatics analysis. The expression level of $I L-1 B$ was up-regulated in EC tissues.

IL-1B, an IL-1 family protein, is an important mediator of inflammatory responses and is involved in cell proliferation and apoptosis during tumor development. The accumulation of IL-1B can assist the body in fighting infection by increasing the expression of adhesion factors on endothelial cells, leading to the migration of leukocytes to sites of infection and altering the set point of the hypothalamic thermoregulatory center, resulting in an elevated body temperature (He et al. 2011a). However, mounting evidence has showed that inflammatory 
Table 3 IL-1B SNPs and risk of EC with or without adjustment for gender and age

\begin{tabular}{|c|c|c|c|c|c|c|c|}
\hline \multirow[t]{2}{*}{ SNP } & \multirow[t]{2}{*}{ Genotypes } & \multirow{2}{*}{$\begin{array}{l}\text { Controls, n } \\
\text { (\%) }\end{array}$} & \multirow{2}{*}{$\begin{array}{l}\text { Cases, n } \\
(\%)\end{array}$} & \multicolumn{2}{|c|}{ Without Adjustment } & \multicolumn{2}{|l|}{ With Adjustment } \\
\hline & & & & OR $(95 \% \mathrm{Cl})$ & $p^{\mathrm{a}}$ & $\mathrm{OR}(95 \% \mathrm{Cl})$ & $p^{\mathrm{b}}$ \\
\hline \multicolumn{8}{|l|}{ rs 2853550} \\
\hline \multirow[t]{3}{*}{ Codominant } & $\mathrm{G} / \mathrm{G}$ & 417 (84.1\%) & $295(76.8 \%)$ & 1.00 & 0.000 & 1.00 & 0.011 \\
\hline & $A / G$ & $71(14.3 \%)$ & 88 (22.9\%) & $1.75(1.24-2.48)$ & & $1.63(1.10-2.42)$ & \\
\hline & $\mathrm{A} / \mathrm{A}$ & $8(1.6 \%)$ & $1(0.3 \%)$ & $0.18(0.02-1.42)$ & & $0.22(0.03-1.86)$ & \\
\hline Dominant (ref: G/G) & $\mathrm{A} / \mathrm{G}+\mathrm{A} / \mathrm{A}$ & 79 (15.9\%) & 89 (23.2\%) & $1.59(1.14-2.23)$ & 0.007 & $1.49(1.02-2.18)$ & 0.041 \\
\hline Recessive (ref: G/G + A/G) & $\mathrm{A} / \mathrm{A}$ & $8(1.6 \%)$ & $1(0.3 \%)$ & $0.16(0.02-1.28)$ & 0.032 & $0.20(0.02-1.70)$ & 0.082 \\
\hline Log-additive & - & - & - & $1.38(1.01-1.89)$ & 0.042 & $1.30(0.92-1.85)$ & 0.140 \\
\hline \multicolumn{8}{|l|}{ rs3136558 } \\
\hline \multirow[t]{3}{*}{ Codominant } & $\mathrm{A} / \mathrm{A}$ & $197(39.7 \%)$ & $140(36.6 \%)$ & 1.00 & 0.620 & 1.00 & 0.980 \\
\hline & $\mathrm{G} / \mathrm{A}$ & $227(45.8 \%)$ & $181(47.4 \%)$ & $1.12(0.84-1.50)$ & & $0.97(0.70-1.35)$ & \\
\hline & $\mathrm{G} / \mathrm{G}$ & $72(14.5 \%)$ & $61(16.0 \%)$ & $1.19(0.80-1.79)$ & & $1.01(0.64-1.59)$ & \\
\hline Dominant (ref: A/A) & $\mathrm{G} / \mathrm{A}+\mathrm{G} / \mathrm{G}$ & $299(60.3 \%)$ & $242(63.4 \%)$ & $1.14(0.87-1.50)$ & 0.350 & $0.98(0.72-1.34)$ & 0.910 \\
\hline Recessive (ref: A/A + G/A) & $\mathrm{G} / \mathrm{G}$ & $72(14.5 \%)$ & $61(16.0 \%)$ & $1.12(0.77-1.62)$ & 0.550 & $1.02(0.67-1.56)$ & 0.920 \\
\hline Log-additive & - & - & - & $1.10(0.91-1.33)$ & 0.340 & $1.00(0.80-1.24)$ & 0.980 \\
\hline \multicolumn{8}{|l|}{ rs1143630 } \\
\hline \multirow[t]{3}{*}{ Codominant } & $\mathrm{G} / \mathrm{G}$ & $352(70.5 \%)$ & $278(72.4 \%)$ & 1.00 & 0.360 & 1.00 & 0.220 \\
\hline & $\mathrm{G} / \mathrm{T}$ & $135(27.1 \%)$ & $92(24.0 \%)$ & $0.86(0.63-1.17)$ & & $0.82(0.58-1.17)$ & \\
\hline & $T / T$ & $12(2.4 \%)$ & $14(3.6 \%)$ & $1.48(0.67-3.24)$ & & $1.74(0.72-4.17)$ & \\
\hline Dominant (ref: G/G) & $\mathrm{G} / \mathrm{T}+\mathrm{T} / \mathrm{T}$ & $147(29.5 \%)$ & $106(27.6 \%)$ & $0.91(0.68-1.23)$ & 0.550 & $0.89(0.64-1.25)$ & 0.510 \\
\hline Recessive (ref: G/G + G/T) & $T / T$ & $12(2.4 \%)$ & $14(3.6 \%)$ & $1.54(0.70-3.36)$ & 0.280 & $1.83(0.77-4.36)$ & 0.170 \\
\hline Log-additive & - & - & - & $0.98(0.76-1.26)$ & 0.860 & $0.98(0.74-1.31)$ & 0.910 \\
\hline \multicolumn{8}{|l|}{ rs1143627 } \\
\hline \multirow[t]{3}{*}{ Codominant } & $\mathrm{A} / \mathrm{A}$ & $124(25.1 \%)$ & $111(30.6 \%)$ & 1.00 & 0.170 & 1.00 & 0.580 \\
\hline & $A / G$ & $266(54.0 \%)$ & $175(48.2 \%)$ & $0.73(0.53-1.01)$ & & $0.87(0.61-1.25)$ & \\
\hline & $\mathrm{G} / \mathrm{G}$ & $103(20.9 \%)$ & $77(21.2 \%)$ & $0.84(0.56-1.23)$ & & $1.05(0.68-1.64)$ & \\
\hline Dominant (ref: A/A) & $\mathrm{A} / \mathrm{G}+\mathrm{G} / \mathrm{G}$ & $369(74.8 \%)$ & $252(69.4 \%)$ & $0.76(0.56-1.03)$ & 0.080 & $0.92(0.65-1.30)$ & 0.640 \\
\hline Recessive (ref: A/A + G/A) & $\mathrm{G} / \mathrm{G}$ & $103(20.9 \%)$ & $77(21.2 \%)$ & $1.02(0.73-1.42)$ & 0.910 & $1.15(0.79-1.68)$ & 0.470 \\
\hline Log-additive & - & - & - & $0.90(0.74-1.09)$ & 0.290 & $1.01(0.81-1.27)$ & 0.900 \\
\hline \multicolumn{8}{|l|}{ rs16944 } \\
\hline \multirow[t]{3}{*}{ Codominant } & $\mathrm{G} / \mathrm{G}$ & $128(25.6 \%)$ & $115(30.0 \%)$ & 1.00 & 0.270 & 1.00 & 0.570 \\
\hline & $\mathrm{G} / \mathrm{A}$ & $269(53.9 \%)$ & $187(48.8 \%)$ & $0.77(0.57-1.06)$ & & $0.90(0.63-1.28)$ & \\
\hline & $\mathrm{A} / \mathrm{A}$ & $102(20.4 \%)$ & $81(21.1 \%)$ & $0.88(0.60-1.30)$ & & $1.11(0.72-1.71)$ & \\
\hline Dominant (ref: G/G) & $\mathrm{G} / \mathrm{A}+\mathrm{A} / \mathrm{A}$ & $371(74.3 \%)$ & $268(70.0 \%)$ & $0.80(0.60-1.08)$ & 0.150 & $0.96(0.68-1.34)$ & 0.790 \\
\hline Recessive (ref: G/G + G/A) & $\mathrm{A} / \mathrm{A}$ & $102(20.4 \%)$ & $81(21.1 \%)$ & $1.04(0.75-1.45)$ & 0.800 & $1.18(0.82-1.72)$ & 0.370 \\
\hline Log-additive & - & - & - & $0.93(0.76-1.12)$ & 0.440 & $1.04(0.84-1.29)$ & 0.720 \\
\hline \multicolumn{8}{|l|}{ rs1143623 } \\
\hline \multirow[t]{3}{*}{ Codominant } & $\mathrm{C} / \mathrm{C}$ & $171(34.5 \%)$ & $154(40.9 \%)$ & 1.00 & 0.150 & 1.00 & 0.280 \\
\hline & $C / G$ & $254(51.2 \%)$ & $173(45.9 \%)$ & $0.76(0.57-1.01)$ & & $0.79(0.57-1.10)$ & \\
\hline & $\mathrm{G} / \mathrm{G}$ & $71(14.3 \%)$ & $50(13.3 \%)$ & $0.78(0.51-1.19)$ & & $1.05(0.65-1.70)$ & \\
\hline Dominant (ref: C/C) & $\mathrm{C} / \mathrm{G}+\mathrm{G} / \mathrm{G}$ & $325(65.5 \%)$ & $223(59.1 \%)$ & $0.76(0.58-1.00)$ & 0.054 & $0.84(0.62-1.15)$ & 0.280 \\
\hline Recessive (ref: C/C + C/G) & $\mathrm{G} / \mathrm{G}$ & $71(14.3 \%)$ & $50(13.3 \%)$ & $0.92(0.62-1.35)$ & 0.660 & $1.19(0.76-1.87)$ & 0.440 \\
\hline Log-additive & - & - & - & $0.85(0.70-1.04)$ & 0.110 & $0.96(0.76-1.20)$ & 0.700 \\
\hline
\end{tabular}

SNP Single nucleotide polymorphism, OR Odd ratio, 95\% CI 95\% confidence interval, Ref Reference category $p^{\text {a }}: p$-values calculated by logistic regression analysis 
Table 4 Haplotype analysis of the IL-1B block formed by rs1143630, rs1143627, rs16944, and rs1143623, and the association with EC risk

\begin{tabular}{|c|c|c|c|c|c|c|}
\hline \multirow{2}{*}{$\begin{array}{l}\text { Haplotype } \\
\text { Block }\end{array}$} & \multirow{2}{*}{$\begin{array}{l}\text { Frequency } \\
\text { (Case) }\end{array}$} & \multirow{2}{*}{$\begin{array}{l}\text { Frequency } \\
\text { (Control) }\end{array}$} & \multicolumn{2}{|c|}{ Without Adjustment } & \multicolumn{2}{|l|}{ With Adjustment } \\
\hline & & & $\mathrm{OR}(95 \% \mathrm{Cl})$ & $p^{a}$ & $\mathrm{OR}(95 \% \mathrm{Cl})$ & $p^{\mathrm{b}}$ \\
\hline GAGC & 0.54 & 0.52 & 1.00 & - & 1 & - \\
\hline GGAG & 0.21 & 0.24 & $0.83(0.65-1.06)$ & 0.130 & $0.99(0.74-1.31)$ & 0.930 \\
\hline TGAG & 0.15 & 0.16 & $0.94(0.72-1.24)$ & 0.680 & $1.00(0.74-1.36)$ & 0.990 \\
\hline GGAC & 0.09 & 0.07 & $1.19(0.83-1.71)$ & 0.350 & $1.28(0.85-1.93)$ & 0.240 \\
\hline
\end{tabular}

OR Odds ratio, $95 \% \mathrm{Cl} 95 \%$ confidence interval

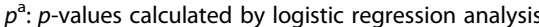

$p^{\mathrm{b}}$ : $p$-values calculated by logistic regression analysis with adjustments for gender and age

responses are closely related to the development of cancer (Werb LMC, Zena 2002). The importance and influence of $I L-1 B$ in tumor development and tumor immunity have been conclusively demonstrated for various diseases (Zheng et al. 2013; Witkin 2002; Upadhyay et al. 2008). In this study, the expression of $I L-1 B$ was dramatically increased in EC tissues compared to normal samples from the GEPIA database, suggesting that $I L-1 B$ promotes malignancy. Therefore, we speculated that $I L$ $1 B$ acts as a stimulating factor during tumorigenesis. Moreover, it is biologically reasonable that functional $I L$ $1 B$ polymorphisms play potential roles in the development of EC.

The wide variation in EC incidence across populations worldwide might be influenced by differences in a

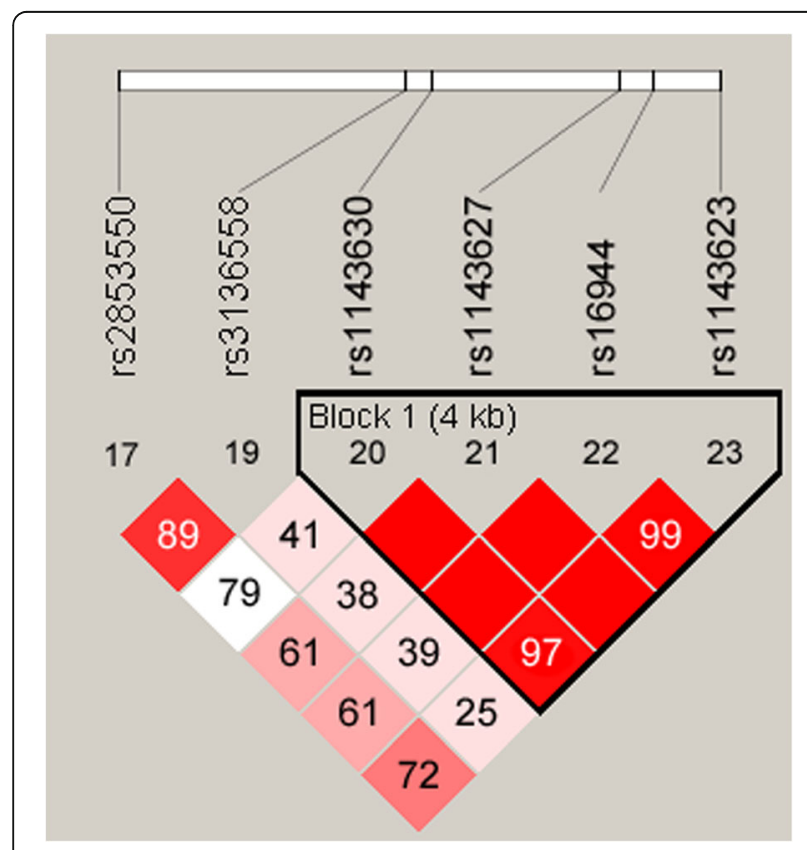

Fig. 1 Illustration of the haplotype block. Four IL-1B polymorphisms (rs1143630-rs1143627-rs16944-rs1143623) mapped to a 4-kb LD block. The red squares in the IL-1B LD block indicate significant linkages between the four SNPs. The numbers in squares are the values of D'. Different numbers show the degree of LD of SNPs. The bright red squares with no number in the middle have the $D^{\prime}$ of 100 group's genetic predisposition. Polymorphisms within the inflammatory and immune factor-encoding $I L-1 B$ gene can result in aberrant IL- $1 \beta$ levels, and their effects on oncogenic processes have been validated in diverse diseases (Ozbabacan et al. 2014). The association of $I L$ $1 B$ rs2853550 with cancer risk has been discussed in several studies. He et al. have reported that $I L-1 B$ rs 2853550 heterozygotes $(\mathrm{OR}=0.34,95 \% \mathrm{CI}: 0.2-0.7$, $p=0.0028)$ and the "A" allele are associated with a significantly reduced risk of colorectal cancer $(\mathrm{OR}=0.43$, 95\% CI: 0.2-0.9, $p=0.0015$ ) (He et al. 2011b). Two other independent studies have revealed that the " $\mathrm{A}$ " allele of $I L-1 B$ rs2853550 might reduce the risk of bowel disease and gastric cancer when was compared with the "G" allele (Nemetz et al. 1999; He et al. 2011b). Our study is the first to provide evidence of the relationship between the SNP rs2853550 and increased EC risk in a northwest Chinese Han cohort. The results showed that the "A/G" genotype of rs 2853550 contributed to an increased EC risk compared with the "G/G" genotype. In accordance with database analyses, we hypothesize that the rs2853550 polymorphism might influence the expression of $I L-1 B$ and thereby affect individual susceptibility to EC. However, Ito and colleagues did not find any association of the $I L-1 B$ rs 2853550 polymorphism with EC risk in Japanese people, which might be attributable to the limited sample size of the Japanese population in that study (75 EC patients and 136 controls) (Ito et al. 2007). Zheng et al. have showed evidence of an association between the $I L-1 B$ rs16944 $\mathrm{G}>\mathrm{A}$ polymorphism and EC risk in a southern Chinese Han population using SNP association analyses (Zheng et al. 2013). Nevertheless, a correlation between rs16944 and EC risk could not be established in our northwest Chinese Han population, which underscores the importance of genetic heterogeneity in population-based research. Further, differences in these studies might also be due to regional disparities, varying sample sizes, and the complexity of genetic and environmental interactions in different ethnic groups. Additionally, we did not find any associations of rs1143643, rs3136558, rs1143630, rs1143627, and rs1143623 with esophageal cancer susceptibility in this 


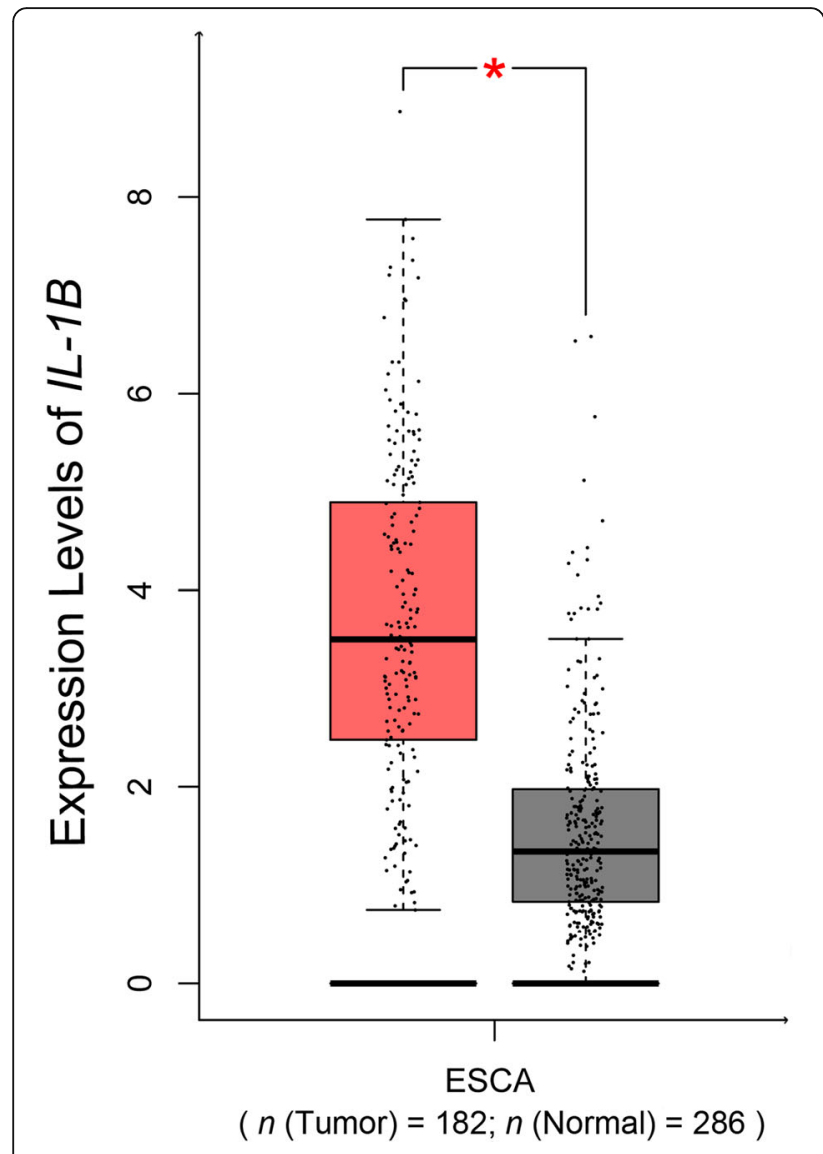

Fig. $2 / L-1 B$ expression patterns in EC tumors and normal tissues. IL-1B expression patterns were assessed using GEPIA (Gene Expression Profiling Interactive Analysis; http://gepia.cancer-pku. $\mathrm{cn} /$ ) database. Expression of IL-1B is increased in EC tumors ( $n=$ 182) compared with normal tissues $(n=286)$. ESCA: Esophageal carcinoma

work. Although the potential functional roles of these SNPs were provided by databases annotating potential predicted regulatory elements, individual variation does not exert their effects alone and their functions might be influenced by genetic backgrounds.

Several limitations in this study should be noted. First, our study found the significant evidence of rs2853550 in correlation to EC development in Chinese Han population of Northwest China. Studies with larger sample size, preferably of different ethnicties, need to be performed to confirm the significant role of rs2853550. Second, we performed a function prediction of rs 2853550 with database, however, the biological function exerted by rs 2853550 need to be further elucidated with well-designed studies. Therefore, further confirmation is necessary to better understand the role of $I L-1 B$ rs2853550 in EC risk.

\section{Conclusions}

In summary, our study provides strong evidence that the $I L-1 B$ rs 2853550 polymorphism could contribute to the risk of EC in the northwest Chinese Han population. These findings indicate a role for $I L-1 B$ during EC development and might provide new targets and strategies for EC risk assessment in the northwest Chinese Han population.

\section{Supplementary information}

Supplementary information accompanies this paper at https://doi.org/10 1186/s10020-020-00178-y.

Additional file 1 Supplementary Table S1. Primers used for the

identification of the IL-1B polymorphisms. Supplementary Table S2.

Functional analysis of selected IL-1B SNPs based on two databases.

\section{Abbreviations}

EC: Esophageal cancer; ESCC: Esophageal squamous cell carcinoma; EAC: Esophageal adenocarcinoma; SNPS: Single-nucleotide polymorphisms; MAF: Minor allele frequency; HWE: Hardy-Weinberg equilibrium; OR: Odds risk; 95\%Cl: 95\% confidence interval; SD: Standard deviation; LD: Linkage disequilibrium

\section{Acknowledgements}

We thank the physicians and medical staff of the Shaanxi Provincial People's Hospital for their contributions and support of this work. We are grateful to all participants for providing blood samples. We also appreciate the reviewers and editors for their patience with this manuscript.

\section{Authors' contributions}

AJ, YW, PH, and YS conceived and designed this research; RMZ, XC, WLR, HD, $A J$, and $Y W$ collected blood samples. RMZ, XC, AJ, YW, PH, and YS performed the experiments; HJL, HHL, AJ, YW, PH, and YS analyzed the data. All authors discussed the results and wrote the manuscript. All authors contributed to the draft and approved the final manuscript.

\section{Funding}

This work was supported by the Key research and development (R \& D) projects of Shaanxi Province In Social development field (2020SF-020).

\section{Availability of data and materials}

The datasets used and analysed during the current study are available from the corresponding author on reasonable request.

\section{Ethics approval and consent to participate}

All participants were informed in writing and verbally of the procedures and purpose of this study. Signed informed consent documents were obtained from both patients and healthy individuals. Study protocols were approved by the Ethics Committee of the First Hospital of Xi'an Jiaotong University and Shaanxi Provincial People's Hospital. Our research also complied with the ethical standards of the Ethics Committee and World Medical Association Declaration of Helsinki. All the subsequent research analyses were carried out in accordance with the approved guidelines and regulations.

\section{Consent for publication}

Not applicable.

\section{Competing interests}

The authors declare that they have no competing interests.

\section{Author details}

'Department of Otolaryngology \& Head Neck, the First Hospital of Xi'an Jiaotong University, \#227 West Yanta Road, Xi'an 710061, Shaanxi Province, China. ${ }^{2}$ Department of Otolaryngology \& Head Neck, Baoji Central Hospital, Baoji 721008, Shaanxi, China. ${ }^{3}$ Department of Digestive System, The First 
Hospital of Xi'an Jiaotong University, Xi'an 710061, Shaanxi, China. ${ }^{4}$ Department of Operation, the First Hospital of Xi'an Jiaotong University, Xi'an 710061, Shaanxi, China.

Received: 16 January 2020 Accepted: 5 May 2020

Published online: 11 June 2020

\section{References}

An J, Zhao J, Zhang X, Ding R, Geng T, Feng T, et al. Impact of multiple alcohol dehydrogenase gene polymorphisms on risk of laryngeal, esophageal, gastric and colorectal cancers in Chinese Han population. Am J Cancer Res. 2015; 5(8):2508-15.

Azim K, Kelleher D, Reynolds J, Mcmanus R. Association of Interleukin 1 Beta gene -511 single nucleotide polymorphism with Eesophageal cancer. Endoscopy. 2004;36:14.

Bird S, Zou J, Wang T, Munday B, Cunningham C, Secombes CJ. Evolution of interleukin-1beta. Cytokine Growth Factor Rev. 2002;13(6):483-502.

Bland JM, Altman DG. The odds ratio. BMJ. 2000;320(7247):1468.

Boyle AP, Hong EL, Hariharan M, Cheng Y, Schaub MA, Kasowski M, et al. Annotation of functional variation in personal genomes using RegulomeDB. Genome Res. 2012;22(9):1790-7

Fairley S, Lowy-Gallego E, Perry E, Flicek P. The international genome sample resource (IGSR) collection of open human genomic variation resources. Nucleic Acids Res. 2019:48(D1):D941-D7.

Gabriel S, Ziaugra L, Tabbaa D. SNP genotyping using the Sequenom MassARRAY iPLEX platform. Curr Protoc Hum Genet. 2009:Chapter 2(Unit 2):Unit 2.12

Geng TT, Xun XJ, Li S, Feng T, Wang LP, Jin TB, et al. Association of colorectal cancer susceptibility variants with esophageal cancer in a Chinese population. World J Gastroenterol. 2015;21(22):6898-904.

He B, Zhang Y, Pan Y, Xu Y, Gu L, Chen L, et al. Interleukin 1 beta (IL1B) promoter polymorphism and cancer risk: evidence from 47 published studies. Mutagenesis. 2011b;26(5):637.

He BS, Pan YQ, Xu YF, Zhu C, Qu LL, Wang SK. Polymorphisms in interleukin-1B (IL-1B) and interleukin 1 receptor antagonist (IL-1RN) genes associate with gastric cancer risk in the Chinese population. Dig Dis Sci. 2011a;56(7):201723.

Hovhannisyan L, Stepanyan A, Arakelyan A. Genetic variability of interleukin-1 beta as prospective factor from developing post-traumatic stress disorder. Immunogenetics. 2017;69(10):703-8.

Ito H, Kaneko K, Makino R, Konishi K, Kurahashi T, Yamamoto T, et al. Interleukin1 beta gene in esophageal, gastric and colorectal carcinomas. Oncol Rep. 2007;18(2):473.

Ito LS, Iwata H, Hamajima N, Saito T, Matsuo K, Mizutani M, et al. Significant reduction in breast cancer risk for Japanese women with interleukin 1B -31 CT/TT relative to CC genotype. Jpn J Clin Oncol. 2002;32(10):398-402.

Jemal A, Siegel R, Ward E, Hao Y, Xu J, Murray T, et al. Cancer statistics, 2008. Ca Cancer J Clin. 2008;58(2):71

Kim YG, Ihm CG, Lee TW, Lee SH, Jeong KH, Moon JY, et al. Association of genetic polymorphisms of interleukins with new-onset diabetes after transplantation in renal transplantation. Transplantation. 2012;93(9):900-7.

Landvik N, Skaug V, Ryberg D, Stangeland L, Haugen A, Zienolddiny S. Association of IL1B gene haplotypes with risk of lung cancer and increased expression of its mRNA in normal lung tissue. Cancer Res. 2008;68(9):3124. https://cancerres.aacrjournals.org/content/68/9_Supplement/3124.article-info.

Langmia IM, Apalasamy YD, Omar SZ, Mohamed Z. Impact of IL1B gene polymorphisms and interleukin 1B levels on susceptibility to spontaneous preterm birth. Pharmacogenet Genomics. 2016;26(11):505-9.

Majeed GS, Glew S, Bidwell J. An association between LSIL and the high secretor phenotype of IL-1beta. Gynecol Oncol. 1999;73(3):359-61.

Mayne ST, Risch HA, Dubrow R, Chow WH, Gammon MD, Vaughan TL, et al. Nutrient intake and risk of subtypes of esophageal and gastric cancer. Cancer Epidemiol Biomarkers Prev. 2001;10(10):1055.

Nemetz A, Nosti-Escanilla MP, Molnár T, Köpe A, Kovács Á, Fehér J, et al. IL1B gene polymorphisms influence the course and severity of inflammatory bowel disease. Immunogenetics. 1999:49(6):527.

Nicklin MJ, Barton JL, Nguyen M, Fitzgerald MG, Duff GW, Kornman K. A sequence-based map of the nine genes of the human interleukin-1 cluster. Genomics. 2002;79(5):718-25.

Ozbabacan SEA, Gursoy A, Nussinov R, Keskin O. The structural pathway of interleukin 1 (IL-1) initiated signaling reveals mechanisms of oncogenic mutations and SNPs in inflammation and cancer. PLoS Comput Biol. 2014; 10(2):e1003470.

Parkin DM, Bray F, Ferlay J, Pisani P. Global cancer statistics, 2002 \&dagger. Ca Cancer J Clin. 2005:55(2):74-108.

Perez-Ramirez C, Canadas-Garre M, Alnatsha A, Molina MA, Robles Al, Villar E, et al. Interleukins as new prognostic genetic biomarkers in non-small cell lung cancer. Surg Oncol. 2017;26(3):278-85.

Sasayama D, Hori H, Teraishi T, Hattori K, Ota M, lijima Y, et al. Possible association between interleukin-1 beta gene and schizophrenia in a Japanese population. Behavioral Brain Funct. 2011;7:35

Sherry ST, Ward MH, Kholodov M, Baker J, Phan L, Smigielski EM, et al. dbSNP: the NCBI database of genetic variation. Nucleic Acids Res. 2001;29(1):308-11.

Tang Z, Li C, Kang B, Gao G, Li C, Zhang Z. GEPIA: a web server for cancer and normal gene expression profiling and interactive analyses. Nucleic Acids Res. 2017:45(W1):W98-W102.

Thomas RK, Baker AC, Debiasi RM, Winckler W, Laframboise T, Lin WM, et al. High-throughput oncogene mutation profiling in human cancer. Nat Genet. 2007;39(3):347-51.

Upadhyay R, Jain M, Kumar S, Ghoshal UC, Mittal B. Potential influence of interleukin-1 haplotype IL-1 beta-511*T-IL-1RN*1 in conferring low risk to middle third location of esophageal cancer: a case-control study. Hum Immunol. 2008:69(3):179-86.

Wang J, Zhang B, Yang Z, Zhou L, Geng T, Li H, et al. Association of gastrointestinal gland cancer susceptibility loci with esophageal carcinoma among the Chinese Han population: a case-control study. Tumor Biol. 2016a; 37(2):1627-33.

Wang Q, Wang L, You J, Yang H, He D, Han L, et al. Multiple genetic variants are associated with the development of esophageal squamous carcinoma in the Chinese population. Int J Clin Exp Pathol. 2016b;9(3):3837-44.

Ward LD, Kellis M. HaploReg: a resource for exploring chromatin states, conservation, and regulatory motif alterations within sets of genetically linked variants. Nucleic Acids Res. 2011;40(D1):D930-D4.

Werb LMC, Zena. Inflammation and cancer. Nature. 2002:420(6917):860.

Witkin SS. Influence of Interleukin-1 receptor antagonist gene polymorphism on disease. Clin Infect Dis. 2002;34(2):204-9.

Yong Y, Lin H. SHEsis, a powerful software platform for analyses of linkage disequilibrium, haplotype construction, and genetic association at polymorphism loci. Cell Res. 2005;15(2):97-8.

Zheng L, Yin J, Wang L, Wang X, Shi Y, Shao A, et al. Interleukin 1B rs16944 G> a polymorphism was associated with a decreased risk of esophageal cancer in a Chinese population. Clin Biochem. 2013;46(15):1469-73.

\section{Publisher's Note}

Springer Nature remains neutral with regard to jurisdictional claims in published maps and institutional affiliations.

Ready to submit your research? Choose BMC and benefit from:

- fast, convenient online submission

- thorough peer review by experienced researchers in your field

- rapid publication on acceptance

- support for research data, including large and complex data types

- gold Open Access which fosters wider collaboration and increased citations

- maximum visibility for your research: over $100 \mathrm{M}$ website views per year

At BMC, research is always in progress.

Learn more biomedcentral.com/submission 